\title{
Gender Differences on the Scholastic Aptitude Test, the American College Test and College Grades
}

\author{
Wei-Cheng Mau and Richard Lynn
}

\begin{abstract}
Gender differences for a nationally representative sample of American college graduates obtained from the Baccalaureate and Beyond 1993-94 study were examined on the Scholastic Aptitude Test and the American College Test, taken at the age of approximately 18 years, and on grades obtained in college at the ages of approximately 18-22 years. It was found that males obtained significantly higher means on the two tests for college entrance and that females obtained significantly higher grades while in college.
\end{abstract}

\section{Introduction}

There is some evidence that, among American 17-18-year-olds, males tend to obtain higher means than females on the Math and Verbal tests of the SAT (Scholastic Aptitude Test, renamed the Scholastic Achievement Test in 1994), the test taken each year by large numbers of applicants to colleges and universities. Arbeiter (1985) and Ramist \& Arbeiter (1986) reported the results for 1984, in which males obtained a higher mean than females by 0.40 SD on the Maths test and by 0.11 SD on the Verbal test. Both the Maths and the Verbal tests of the SAT are in multiple choice format. The Maths test consists of arithmetic, algebra and geometry. The Verbal test consists of vocabulary, verbal reasoning and verbal comprehension. A similar result has been reported for Germany by Stumpf \& Jackson (1994) who found that, among approximately 200,000 applicants given a number of tests for admission to medical schools, males obtained a higher mean on reasoning than female by $0.56 \mathrm{~d}$ while females obtained a higher mean on memory by $0.50 \mathrm{~d}$. The male advantage on reasoning in this data set is consistent with the American data on the SAT in so far as the SAT is largely a test of general reasoning ability. A further study obtaining similar results comes from Estonia in which it was found that, among applicants for university, males obtained higher mean scores on admission tests covering verbal, reasoning and spatial abilities, and general knowledge (Allik et al., 1999).

In the American research literature, despite the report of the higher means obtained by males on the SAT, there have been some reports that females tend to obtain better grades than males during their years as college undergraduates (Linn, 1990; Young, 1991, 1994). A similar gender difference has been found in Europe in a 26-nation study of the historical knowledge and grades of 15-year-olds, in which males obtained higher mean scores on knowledge test, but females obtained higher grades (Wilberg \& Lynn, 1999). Thus, the general picture from the research literature is that among older adolescents males obtain higher means on tests of reasoning abilities but females obtain higher grades. In this paper, we present further evidence on these apparent gender differences.

\section{Methods}

The data to be reported are derived from the Baccalaureate and Beyond Study of 1993-94 (B\&B; National Center for Educational Statistics, 1996). This consists of a survey of a representative sample of American college graduates who obtained their bachelor degrees between July 1, 1992, and June 30, 1994. The sample were followed up and a variety of information obtained from them approximately 1 year after graduation. The data to be reported here consist of the scores on the SAT or the alternative 
ACT (American College Test) taken as part of the college entrance process around the year 1988, and the Grade Point Average (GPA) obtained during the years at college.

The initial sample consists of approximately 12,500 graduates. Approximately 2400 members of this initial sample were ineligible at the time of the first follow-up interview, resulting in a final sample of 10,080 college graduates. The B\&B sample is part of the National Postsecondary Student Aid Study (US Department of Education, 1996), sample $(n=79269)$. This employed a stratified multi-stage sample design with post-secondary institutions as the first-stage units and students within schools as the second-stage units. The institution sample was stratified by public versus private, highest degree offered, size of enrollment in professional programmes, graduate student enrollment and numbers of bachelor's degrees awarded in education. A total of 1386 institutions were sampled from the 50 American states, the District of Columbia and Puerto Rica. Full details of the sample and the sampling procedures are given in National Postsecondary Student Aid Study. The data are available on CD-Rom, from which the analyses to be reported have been made. The sample is weighted to adjust for sampling error.

\section{Results}

The results of the SAT and ACT tests and the GPAs for males and females are presented in Table I. This gives the numbers, means and standard deviations on the tests, the $d$ (the difference between the male and female means divided by the pooled standard deviation) and the statistical significance of the male-female differences tested by analysis of variance. The first three rows in Table I give the means for males and females for the Maths (M) and Verbal (V) tests of the SAT, and for the ACT. It will be noted that males obtained significantly higher means on all three tests and that the male advantage is greatest on the SAT-M and least on the SAT-V. The bottom row gives the GPAs, for which it will be noted that females obtained a significantly higher mean than males.

TABLE I. Gender differences on the SAT, the ACT and GPAs

\begin{tabular}{|c|c|c|c|c|c|c|c|c|}
\hline \multirow[b]{2}{*}{ Test } & \multicolumn{3}{|c|}{ Males } & \multicolumn{3}{|c|}{ Females } & \multirow[b]{2}{*}{$d$} & \multirow[b]{2}{*}{$F$} \\
\hline & $n$ & Mean & SD & $n$ & Mean & SD & & \\
\hline $\mathrm{SAT} / \mathrm{M}$ & 1762 & 561.7 & 107.8 & 2168 & 516.6 & 104.5 & 0.41 & $171.16^{\star}$ \\
\hline SAT/V & 1762 & 492.7 & 100.4 & 2168 & 478.7 & 104.6 & 0.14 & $17.37^{\star}$ \\
\hline ACT & 1582 & 22.79 & 4.88 & 1971 & 21.63 & 5.01 & 0.23 & $47.39^{\star}$ \\
\hline GPA & 4256 & 3.12 & 0.44 & 5494 & 3.25 & 0.43 & 0.30 & $235.52^{\star}$ \\
\hline
\end{tabular}

$\star P<0.001$

\section{Discussion}

The results of this study confirm the rather fragmentary evidence summarised in the introduction. They suggest that, in late adolescence and early adulthood, males obtain higher means than females on aptitude tests consisting largely of tests of general cognitive and reasoning abilities for college entrance, but females obtain higher grades during their years at college. The explanations for these gender differences remain to be considered. As regards the higher mean obtained by males on the Maths aptitude test, this result is consistent with a number of previous studies reviewed in the meta-analysis carried out by Hyde et al. (1990), who found that among samples with above average mathematical ability the size effect favouring males was approximately 0.43 . The size effect in the present study of 0.41 is virtually identical. As regards verbal ability, there is no general consensus on the gender difference. Maccoby \& Jacklin (1974) in the first major literature review of this issue concluded that females have an advantage 
in verbal ability of 0.23 . The next major literature review was carried out by Hyde \& Linn (1988) and concluded that females have an advantage of 0.11 . However, in a recent review of the literature, Kimura $(1999$, p. 11) concludes that 'Contrary to popular opinion, adult women are not superior on all or most verbal tasks'. A third view proposed by Lynn (1994) on the basis of the verbal scales of the Wechsler tests is that males have higher verbal abilities by 0.17 . This view is supported by previous studies on the SAT such as that for the year 1984 by Ramist \& Arbeiter (1986) who found a male advantage of 0.11 . This is very close to the present result showing a male advantage of 0.14 .

So far as the higher grades obtained by females at college are concerned, two factors may be involved. First, several studies have found that females tend to have a stronger work ethic than males (Farmer, 1983; Neville \& Super, 1988; Linn, 1990; Watson \& Stead, 1990; Luzzo, 1994). This is likely to be expressed in a more conscientious performance of course work, on which grades are normally based. A second factor may be that females tend to be better than males on essay writing and spelling, as shown in the meta-analysis carried out by Hyde \& Linn (1988). These aptitudes are not tested in the SAT or the $A C T$, but are likely to contribute to grades.

The general conclusion indicated by the results of the present study and previous research is that the average differences in educational attainment of males and females in late adolescence and early adulthood will depend on the extent to which assessments are based on cognitive tests and on coursework. The more assessments are based on cognitive tests, the greater the male advantage, while the more assessments are based on coursework, the greater the female advantage. In Britain, there has been much discussion and concern in recent years about the improvement of girls and young women in GCSE and A-level performance, and the increasingly poorer performance of boys and young men. The research reviewed and reported in this paper suggests that this may well be due to a shift towards a greater contribution of coursework to the grades obtained in these assessments.

\section{REFERENCES}

Allik, J., Must, O., \& Lynn, R. (1999). Sex differences in general intelligence among high school graduates: some results from Estonia. Personality and Individual Differences, 26, 1137-1141.

Arbeiter, S. (1985). Pro" les, college bound seniors. New York: College Entrance Examination Board.

Farmer, H.S. (1983). Career and homemaking plans for high school youth. Journal of Counselling Psychology, 30, 40-45.

Hyde, J.S., \& Linn, M.C. (1988). Gender differences in verbal ability: a meta-analysis. Psychological Bulletin, 104, 53-69.

Hyde, J.S., Fennema, E., \& Lamon, S.J. (1990). Gender differences in mathematical performance: a metaanalysis. Psychological Bulletin, 107, 139-155.

Kimura, D. (1999). Sex and cognition. Cambridge: MIT Press. Linn, R.L. (1990). Admissions testing: recommended uses, validity, differential prediction and coaching. Applied Measurement in Education, 3, 297-318.

Luzzo, D.A. (1994). An analysis of gender and ethnic differences in college students' commitment to work. Journal of Employment Counselling, 31, 38-45.

Lynn, R. (1991). The secret of the miracle economy. London: Social Affairs Unit.

Lynn, R. (1994). Sex differences in intelligence and brain size: a paradox resolved. Personality and Individual Differences, 17, 257-271.

Maccoby, E.E., \& Jacklin, C.N. (1974). The psychology of sex differences. Stanford: Stanford University Press.

National Center for Educational Statistics (1996). Baccalaureate and beyond longitudinal study: 1993/94 first follow-up methodology report. (Report No. NCES 96-149). Washington DC: U.S. Department of Education. 
Neville, D.S., \& Super, D.E. (1988). Career maturity and commitment to work in university students. Journal of Vocational Behavior, 32, 139-151.

Ramist, L., \& Arbeiter, S. (1986). Pro" les, college bound seniors. New York: College Entrance Examination Board.

Stumpf, H., \& Jackson, D.N. (1994). Gender-related differences in cognitive abilities: evidence from a medical school admissions testing program. Personality and Individual Differences, 17, 335-344.

U.S. Department of Education (1996). National Postsecondary Student 1995-1996 Aid Study. Washington DC: Government Printing Office.

Watson, M.B., \& Stead, G.B. (1990). Work-role salience of South African adolescents. Journal of Vocational Behavior, 36, 249-257.

Wilberg, S., \& Lynn, R. (1999). Sex differences in historical knowledge and school grades: a 26 nation study. Personality and Individual Differences, 27, 1221-1230.

Young, J.W. (1991). Gender bias in predicting college academic performance: a new using item response theory. Journal of Educational Measurement, 28, 37-47.

Young, J.W. (1994). Differential prediction of college grades by gender and ethnicity: a replication study. Educational and Psychological Measurement, 54, 1022-1029. 